\title{
A European Research Program on Shelf Edge EXCHANGE PROCESSES
}

\author{
By Christopher N.K. Mooers, Erwin Suess and Klaus-Gunther Barthel*
}

$T$ HE EUROPEAN COMMISSION is conducting a large-scale, cooperative marine research program over its adjacent continental margins and seas. Although the Commission controls only $\sim 4 \%$ of all research funds expended in the European Union (EU), this represents a substantial block of the research funds contributed by member nations in proportion to their individual GNPs. Since 1989 the European Union has supported basic and applied marine research in the European seas and the development of relevant technology in the context of the "Marine Science and Technology (MAST)" program. The third phase of this program, between 1994 and 1998, provides ca. $\$ 320 \mathrm{M}$ (USA) for international cooperative research activities throughout Europe. MAST finances curiosity-driven, contextual (focused, goal-oriented) research by consortia from at least two different EU member countries with the requirement that partners provide matching funds. In reality, many more than the minimum of two partners are usually involved. Small projects have between 4 and 6 partners. those of moderate size between 6 and 10, and as many as 40 to 60 partners make up the large to very large projects. Each is coordinated by one institution. The assessment of matching

Christopher N.K. Mooers, Rosenstiel School of Marine and Atmospheric Science, University of Miami. 4600 Rickenbacker Cswy., Miami, FL 33149, USA: Internet: cmooers@ rsmas.miami.edu: Erwin Suess, Geomar Forschungszentrum fur Marine Geowissenschaften, WischhofstraBe 13, D24148 Kiel, Germany; Internet: esuess@geomar.de; Klaus-Gunther Barthel, European Commission, DG XIt/D-3, Marine Science and Technology Programme. Rue de la Loi 200. B-1049 Brussels. Belgium: Internet: klaus-guenther.barthel@dg12.cec.be

* This article represents the author's opinion. not that of the European Commission. funds is two-tiered. For partners from educational institutions the total additional costs for the project may be granted by the EU, but for industrial and noneducational, governmental or independent research organizations, $50 \%$ of the project cost may come from the EU, and the additional $50 \%$ must be the partner"s own contribution and be documented at the time of proposal submission in labor, equipment, time, infrastructure, or some other approach to estimating costs. Approximately $40 \%$ of the program's funds are dedicated to process- and problemoriented ecosystem studies, $22 \%$ to strategic marine research (e.g., coastal zone science and engineering), $30 \%$ to marine technology (e.g., instrumentation development, vehicles, systems, imaging, ocean acoustics, robotics, communication, geotechnics, and bioactive substances), and $8 \%$ to infrastructure generation (e.g., data management, standardization, design studies, conferences and workshops, courses, and fellowships).

\section{MAST Scientific and Programatic Strategy}

The geographic coverage of MAST extends through the eastern North Atlantic including the European Arctic and the Baltic and Mediterranean Seas. The disciplinary scope includes physical oceanography, biogeochemistry, marine ecosystems, sedimentology, coastal engineering, and marine technology. MAST is a competitive program requiring crossborder partnerships between academic, industrial, and governmental scientists and engineers of the more-developed and less-developed EU and associated nations. In addition to addressing scientific objectives of clear societal relevance, MAST aims to develop technological and scientific infrastructure and expertise that will bring EU ocean science to a new level of excellence and cooperation through creating "critical mass" effects. The societal relevance most obviously resides in scientific management related to coastal seas, ocean pollution, natural hazards, consequences of climate change, and industrially relevant technological developments.

The program has launched particularly large integrated projects in the Mediterranean, Baltic, Canary-Azores region including Gibraltar, and the NE Atlantic shelf edge. The latter is more closely examined here. Because the aggregate level of EU effort is well beyond anything familiar to U.S. coastal ocean scientists, except perhaps in their most ambitious aspirations, it is of interest to review the scientific and programatic strategy and status of the shelf edge exchange research program within MAST and contemplate its implications for the future of U.S. coastal ocean science.

\section{The Integrated Project on Shelf Edge Exchange Processes}

The large, integrated project on shelf edge exchange processes in the NE Atlantic is composed of a number of individual projects that are linked by regular information exchange via workshops. The "2nd EU Workshop on Exchange Processes at the Continent-Ocean Margins in the North Atlantic" was held 22-24 February 1995 at Knokke, Belgium. The themes of the workshop centered around eight individual projects: SEEP, ENAM, STEAM, ICOS, EHUX, SEFOS, OMEX and MORENA. The project SEEP, unlike its namesake in the United States, deals with gas and fluid seepage along the continental margin. It is one of the smallest projects with five partners from four countries. The project ENAM (European North Atlantic Margin: Sediment Pathways, Processes and Fluxes) looks at slope stability or rather instability and failure along the margins, particularly off 
Norway. It has nine partners from seven countries. Sediment Transport on European Atlantic Margins (STEAM) aims at determining the modes of sediment transport to the deep sea off Portugal and the Canary Islands. It consists of six partners from five countries. The five partners from four countries in ICOS (Investigations of Calanus finmarchicus migrations between Oceanic and Shelf waters) investigate the migration of a dominant zooplankter (Calanus finmarchicus) between oceanic and shelf seas off northwest Europe. The growth and distribution of the coccolithophorid Emiliania huxlevi is the central topic of the 13 partners from 5 countries in EHUX (Coccolithophoid dynamics: The European Emiliania Huxlevi programme). SEFOS (Shelf Edge Fisheries and Oceanography Studies) is funded under the EU fisheries program and looks at the relationship between the distributions and migrations of commercially important fish species and physical oceanographic patterns along the European shelf edge. The objectives of MORENA (Multidisciplinary Oceanographic Research in the Eastern Boundary of the North Atlantic) are to understand quantitatively the physical, chemical, and biological processes in the water column that are relevant for the transfer of matter, momentum, and energy across and along the shelf edge and the slope west of the Iberian peninsula. Eight partners from four countries are involved. OMEX (Ocean Margin Exchange) is by far the largest project. With 33 institutions from 10 countries comprising $>40$ principal scientists, it is a truly multidisciplinary, multinational, and multiyear project. Even though the grants for such projects run initially for $3 \mathrm{yr}$ only, an option exists to submit a continuation proposal for another $3 \mathrm{yr}$. However, funding is by no means automatic but depends on a thorough review, as if it were a new project. OMEX contains the following subprojects: 1) physical processes at the shelf edge. 2) biological processes, 3) biogeochemical cycling. 4) benthic processes, and 5) air-sea exchange. It encompasses most fields of specialty known in marine science. In summary, the total number of principal scientists in all 8 projects focused on shelf edge processes approaches 90 , and the funding level is several mil- lion dollars per year. The component projects are either characterized as topical or as subregional in geographic scope. They deal with such different topics as sediment transport processes and fluxes, current patterns, biogeochemical turnover, and migration patterns and life cycles of dominant species. To a significant degree. a holistic description of shelf edge exchange processes is being created by the summation and coordination of the individual projects. The geographic coverage extends along the entire Atlantic coast of Europe and northwest Africa, from the Canary Islands to Spitzbergen.

Of considerable interest is the Europeans' intensive use of numerical circulation models as complements to the observational projects for process understanding and data interpretation. It is especially significant that multiple models (including some of the U.S. community models) are being compared and evaluated against observations. At the same time, some of the numerical circulation models have incorporated marine ecosystem submodels (including higher trophic levels) that demonstrate, even at this early stage, tantalizing potential for hypothesis development and testing. As one of the two U.S. guest scientists at the EU workshop at Knokke, Belgium, the first author presented an invited talk surveying contemporary and planned U.S. physical studies of shelf edge exchange processes. The heavy reliance of U.S. studies on substantial arrays of observations and limited (if any) utilization of numerical models evoked comments from EU scientists; this difference in scientific strategy may reflect their tradition of theoretical and numerical modeling studies in such areas as the North Sea.

The EU scientists are essentially using all of the shipboard, moored, Lagrangian, and satellite remote sensing technologies in general use in the United States, plus some of their own developments. Effective scientific communications have been established within disciplines on a multiinstitutional and multinational basis. However. the EU scientists are struggling. as are U.S. scientists, with fully effective communications across disciplinary boundaries, although there are notable, pioneering efforts to do so, perhaps best epitomized by the multidiscipli- nary modeling mentioned above. Notably the EU scientists have drawn upon the results of U.S. shelf edge exchange process studies. For example, in their studies off the Iberian peninsula, they have built upon the analogues that can be drawn with the eastern boundary current eddies. jets, and trans-shore filaments studied off California in the 1980s. Similarly, in the study of possible carbon depocenters over the continental slope, parallels are drawn to the results of the U.S. SEEP Program in the Middle Atlantic Bight.

\section{Future Outlook and Implications for the United States}

Now that EU scientists have established considerable momentum in their shelf edge exchange process studies and achieved an integration that goes beyond the level established in the United States, they are challenging U.S. scientific leadership in this topical area. which will be quite significant if the momentum is sustained for several more years. In the past. to foster their own expertise, the EU programs have eschewed direct collaboration with non-EU partners (e.g.. the United States). However, having achieved their present level of expertise and momentum, the EU programs' policy now permits collaborative research with non-EU partners where it is beneficial for the European scientific or industrial development. As MAST-III moves ahead, the pressure is mounting to deliver societally relevant products. The program has consequently become more applications-oriented after the latest revision in focus. It could be of appreciable value for the United States to track the efforts of EU scientists to transfer information and technology to industrial. commercial, and governmental users. Moreover, both the EU and the United States should actively search for areas in which cooperation could be established more closely to mutual benefit. Marine science is, after all, an environmentally relevant science and cannot be viewed strictly on regional levels. Only integrated approaches and world-wide cooperation can result in an appropriate solution of global problems. This goal entails a revision of national and international research structures when and where necessary and opportune. 